\title{
CLOSED-FORM SOLUTIONS OF LARGE DEFLECTION FOR A GUYED CANTILEVER COLUMN PULLED BY AN INCLINATION CABLE
}

Jong-Dar Yau

Department of Architecture, Tamkang University 10620, Taiwan., jdyau@mail.tku.edu.tw

Follow this and additional works at: https://jmstt.ntou.edu.tw/journal

Part of the Civil and Environmental Engineering Commons

\section{Recommended Citation}

Yau, Jong-Dar (2010) "CLOSED-FORM SOLUTIONS OF LARGE DEFLECTION FOR A GUYED CANTILEVER COLUMN PULLED BY AN INCLINATION CABLE," Journal of Marine Science and Technology. Vol. 18: Iss. 1, Article 16. DOI: $10.51400 / 2709-6998.1874$

Available at: https://jmstt.ntou.edu.tw/journal/vol18/iss1/16

This Research Article is brought to you for free and open access by Journal of Marine Science and Technology. It has been accepted for inclusion in Journal of Marine Science and Technology by an authorized editor of Journal of Marine Science and Technology. 
CLOSED-FORM SOLUTIONS OF LARGE DEFLECTION FOR A GUYED CANTILEVER COLUMN PULLED BY AN INCLINATION CABLE

\section{Acknowledgements}

The author is grateful to anonymous referees for their valuable comments to this paper. Parts of the theory and illustrative examples presented in this study have been referred to as the extended abstracts entitled "Large Deflection Analysis of a Guyed Column Pulled by a Cable," presented at the Proceedings of IASS-APCS Symposium on New Perspectives for Shell \& Spatial Structures, National Taiwan University, Taipei, Taiwan, Oct. 22-25, 2003 [25]. 


\title{
CLOSED-FORM SOLUTIONS OF LARGE DEFLECTION FOR A GUYED CANTILEVER COLUMN PULLED BY AN INCLINATION CABLE
}

\author{
Jong-Dar Yau*
}

Key words: elastica, guyed column, large defection.

\begin{abstract}
Geometric non-linearity becomes an issue of great concern that cannot be overlooked in the analysis of cable-supported structures since their material properties may be in an elastic range but they exhibit nonlinear behavior when loaded. This study intends to present an analytical approach for analyzing the large deflection behavior of a guyed column pulled by a pre-tensioned cable at different stages of installation. The column is assumed to be naturally straight and inextensible, and each cable is modeled as an equivalent tensile bar neglecting the sag effect due to self-weight. Based on an elliptic integral formulation, closed-form solutions are derived for the large deflection of a guyed column pulled by a pre-tensioned cable with different deformed configurations. The interaction between the nonlinear deflection of the guyed column and the sequentially applied cable forces are fully taken into account. The analytical result indicates that the larger aspect ratio $(h / l)$ of the cable anchor distance $(h)$ to the column height $(l)$ may result in smaller critical tip slope.
\end{abstract}

\section{INTRODUCTION}

Because of the advancement in material technologies for producing steel wires of reliable quality and high strength, cable supported structures are widely used in various constructions including suspension bridges, cable-stayed bridges, dome buildings, cable-supported roofs of large stadiums, guyed towers for telecommunications, etc. The enhancement in structural performance brought by the use of pre-tensioned cables has enabled us to design structures of lighter weights and richer aesthetic appearance. However, most cablesupported structures are featured by the fact that they are flexible structures. The reason for such a phenomenon is that the pre-tensioned cables tend to strengthen the structural sys-

Paper submitted 09/12/08; accepted 03/30/09. Author for correspondence: Jong-DarYau(e-mail: jdyau@mail.tku.edu.tw).

*Department of Architecture, Tamkang University 10620, Taiwan. tem, allowing it to achieve the design goals usually in a more creative way. The reduction in the overall weight of the structural system is accompanied by the reduction in the stiffnesses of the structural components. As a result, geometric nonlinearity becomes an issue that cannot be overlooked in the analysis of the cable-supported structures. One typical example is the nonlinear deformational behavior of communication towers guyed by cables under both the construction stages and service conditions. In general, the non-linear behavior of a guyed structure is caused by the change of stretching forces existing in the guy cables or the large deformations of certain components of the structure under the action of wind loads or earthquakes.

In the literature, the large deflection behavior of beams or elasticas continues to be a subject of intensive research. Numerous researchers have studied the problem of elasticas under different conditions and using different methods of solution. For simple beams allowed to slide freely over the roller end, Conway [5] and Gospodnetic [8] derived closedform solutions for simply supported beams subjected to a point load at the center. Wang and Kitipornchai [19] proposed the shooting-optimization technique for studying the large deflection and postbuckling behaviors of structural members. Chucheepsakul et al. [2-4] investigated the large deflection behaviors of beams under moment gradient using the elliptic integral method. The results obtained were verified by those independently generated by other numerical methods. Considering a simple beam with an elastically rotational restraint at one end, Wang et al. [20] studied the large deflections of a beam subjected to a non-central point load. Considering variable-arc-length elasticas subjected to two moments at the supports, Chucheepsakul et al. [4] investigated the large deflection behavior of double curvature bending. For this kind of bending problem, they found that the elastica can form a single loop or snap-through bending for some unstable equilibrium configurations. By considering the effects of both compression and bending, Williams [21] presented an analytical approach for analyzing the nonlinear behavior of the members of a rigid jointed plane framework with finite deflections, in which the famous Williams' toggle was thoroughly studied. Recently, Kalaga and Adluri [10] obtained a closed-form solution for the large-deflection response of an 
eccentrically loaded beam-column including the bowing effect and initial imperfection. Lee and Oh [12] solved the elastica problem and buckling load of simple tapered columns subjected to a compressive end load by numerical methods. Their results indicated that the strongest column can be identified for each taper and cross-sectional shape by varying the section ratio. The analytical solutions obtained by Ohtsuki and Ellyin [14] for the large deflection response of a square frame with rigid joints were shown to be fairly close to those obtained experimentally. For a cantilever beam subjected to an end rotational load non-conservative loads, exact solutions were presented by Nageswara and Venkateswara [13] and by Villaggio [18]. Adopting the elastica solution of a beam-column structure, Hartono [9] investigated the large displacement post-buckling behavior of a column braced at the center. Depending on the brace stiffness, different symmetrical and antisymmetrical post-buckling paths were shown to exist. By the concept of an equivalent peseudo-linear system, Ferits [6] proposed a procedure for analyzing the large deflections of beams with distributed loads and variable stiffnesses. Kuznetsov and Levyakov [11] proposed a complete solution of the stability problem for elastica of Euler's column and established the ranges of the compressive force corresponding to stable equilibrium configurations of the column.

To the knowledge of the author, relatively few analytical works have been conducted on the large deflection behavior of a guyed structure with inclined cables installed at different stages. For this kind of problems, an important issue in analysis is that the cable forces applied at each stage on the structure depend on the deformation of the guyed column and the locations of cable supports. In this study, we shall assume that the classical Bernoulli-Euler beam theory applies for the guyed column and that the materials remain always elastic. By modeling the cables each as an equivalent tensile bar, neglecting the sag effect of the cable caused by self-weight [7], the governing differential equation for the fundamental problem of a column subjected to the pull action of an inclined cable is presented. By the elliptic integral method, analytical solutions are derived for the tip displacement of the guyed column and the cable force. The present theory provides an accurate tool for treating a large class of problems involving large deflections of guyed structures, such as cable-stayed bridges, radio masts, cable-supported roofs, etc. It is characterized by the fact that the interaction between the nonlinear deflection of the guyed column and the sequentially applied cable forces are fully taken into account. The analytical solutions presented herein for a guyed column serve as benchmarks for calibrating solutions obtained by other numerical methods.

\section{FORMULATION OF THE PROBLEM}

The most fundamental problem for cable-supported structures is the cantilever column $O B$ laterally guyed by a cable $A B$ shown in Fig. 1. According to the degree of stretching in the cable force, the column will be bent by a combination of

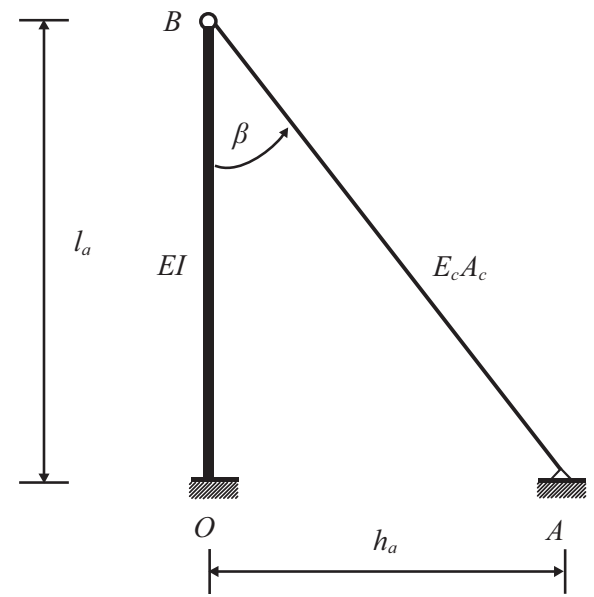

Fig. 1. A guyed column.

axial compression and transverse force acting at its tip point. The initially included angle between the undeformed column and the cable is $\beta$, and the distance between the cable support $A$ and the column base $O$ is $h_{a}$. Consider the guyed column in the deformed configuration, as shown in Fig. 2. The column is bent by an inclined force $T$ exerted by the cable with an inclination angle $\alpha$. The tip slope of the deformed column is $\theta_{0}$. Prior to the mathematical formulation for the guyed column pulled by an inclined cable, the following assumptions are made in the large deflection analysis:

(1) The material is elastic and homogeneous during the deformation process;

(2) The column is naturally straight and inextensible;

(3) By neglecting the cable sag effect due to self-weight, the cable is modeled as an equivalent tensile bar with axial rigidity $E_{c} A_{c}$

(4) The warping of cross section [20-22] is assumed to be negligible in large deformation analysis for the guyed column, that is, the classical Bernoulli-Euler beam theory with plain sections is applied to the column during large deformation.

\section{GOVERNING EQUATION}

Consider an arc length $s$ measured from the tip $B$ of the column in the deformed configuration, as shown in Fig. 2(a). The slope of the column at section $s$ is $\theta$. In accordance with the shear equilibrium condition for the part of the column with arc length $s$, as shown in Fig. 2(b), the governing differential equation for the column subjected to an inclined cable force $T$ can be written as $[1,16,19]$

$$
E I \frac{d^{2} \theta}{d s^{2}}+T \sin (\theta+\alpha)=0
$$

where $E I$ denotes the flexural rigidity of the column. By let- 


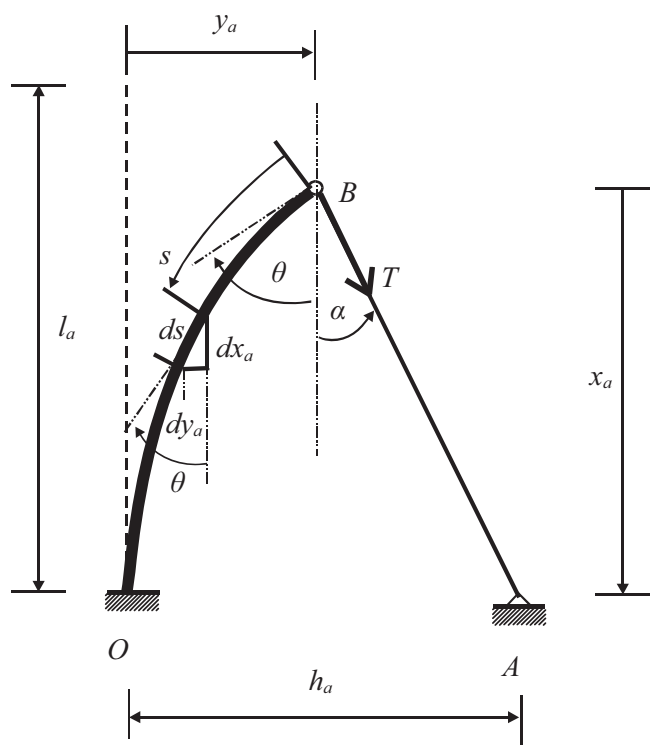

(a)

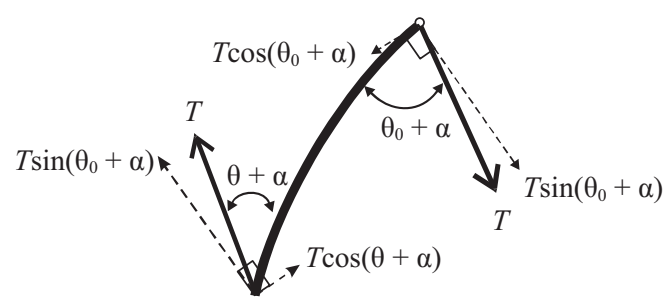

(b)

Fig. 2. A cantilever column pulled by an inclined cable: (a) deformed configuration; (b) force equilibrium.

ting $l_{a}$ denote the length of the column, the boundary conditions for the free and fixed ends are

$$
\begin{array}{ll}
s=0: & \theta=\theta_{0}, \quad d \theta / d s=0 \\
s=l_{a}: \quad & \theta=0
\end{array}
$$

As can be seen, the curvature $d \theta / d s$ at the tip $B$ of the column is zero, since the bending moment vanishes at the free end. By multiplying (1) by $d \theta / d s$ and then integrating with respect to $\theta$, one can derive the following differential equation:

$$
(d \theta / d s)^{2}=2 k^{2} \times\left[\cos (\theta+\alpha)-\cos \left(\theta_{0}+\alpha\right)\right]
$$

where $k^{2}=T / E I$. Using the identity: $\cos \chi=1-2 \sin ^{2}(\chi / 2)$, Eq. (3) can be rewritten in the following form:

$$
d s=-\frac{d \theta}{2 k \sqrt{\sin ^{2}\left[\left(\theta_{0}+\alpha\right) / 2\right]-\sin ^{2}[(\theta+\alpha) / 2]}}
$$

where the minus sign on the right hand side means that the slope $\theta$ shown in Fig. 2(a) is a decreasing function with respect to the arc length $s$. By the hypothesis of an inextensible bar and using the boundary conditions in (2), one may integrate (4) to obtain the relation for the column length $l_{a}$ and tip slope $\theta_{0}$ of the deformed column as $[1,16]$ :

$$
l_{a}=\int_{0}^{l_{a}} d s=\frac{-1}{2 k} \int_{\theta_{0}}^{0} \frac{d \theta}{\sqrt{\sin ^{2}\left[\left(\theta_{0}+\alpha\right) / 2\right]-\sin ^{2}[(\theta+\alpha) / 2]}}(5)
$$

which forms the basis of the present analysis.

\section{SOLUTION: AN ELLIPTICAL INTEGRAL APPROACH}

To compute the tip slope $\theta_{0}$ and the inclination angle $\alpha$ of the guyed column from (5), we need to introduce two new parameters $p$ and $\phi$ defined as follows [1]:

$$
\begin{aligned}
& p=\sin \frac{\theta_{0}+\alpha}{2} \\
& \sin \frac{\theta+\alpha}{2}=p \sin \phi
\end{aligned}
$$

Then one can transform the integral appearing in (5) into a characteristic equation with elliptic integral type and then calculate the elliptic integral for various values of $p$. In accordance with (6), the boundary conditions in (2) can be transformed to

$$
\begin{aligned}
& \theta=0: \quad \phi=\phi_{0}=\arcsin \left[\frac{\sin (\alpha / 2)}{p}\right] \\
& \theta=\theta_{0}: \quad \phi=\pi / 2
\end{aligned}
$$

By considering the differentiation of $(6 b)$ and using the definition of (6a), the relationship between $d \theta$ and $d \phi$ can be derived as

$$
d \theta=\frac{2 p \cos \phi}{\sqrt{1-p^{2} \sin ^{2} \phi}} d \phi
$$

Substituting (6), (7), and (8) into (5) yields

$$
\begin{aligned}
& l_{a}=\frac{F\left(p, \phi_{0}\right)}{k}=\frac{F_{e}(p, \pi / 2)-F_{e}\left(p, \phi_{0}\right)}{k} \\
& F_{e}(p, \pi / 2)=\int_{0}^{\pi / 2} \frac{d \phi}{\sqrt{1-p^{2} \sin \phi^{2}}} \\
& F_{e}\left(p, \phi_{0}\right)=\int_{0}^{\phi_{0}} \frac{d \phi}{\sqrt{1-p^{2} \sin \phi^{2}}}
\end{aligned}
$$


where $F_{e}(p, \pi / 2)$ is a complete elliptic integral of the first kind, and $F_{e}\left(p, \phi_{0}\right)$ an incomplete elliptic integral of the first kind. For a given $p$, the values of the elliptic integrals can be found from the tabulated results in many mathematical handbooks [17].

\section{GEOMETRY CONSIDERATIONS}

According to the expression in (9), for given values of $p$ and $\phi_{0}$, or $\theta_{0}$ and $\alpha$, as shown in (6), the reduced length $k l_{a}$ is determined by (9). The stretching force $T$ needed to keep the column in such an equilibrium configuration is $T=E I k^{2}$ by the definition given in Section II. However, as shown in Fig. 2(a), for the analysis of a column subjected to the stretching of an inclined cable, the inclination angle $\alpha$ depends not only on the tip coordinates $\left(x_{a}, y_{a}\right)$ of the column in the deformed configuration, but also on the geometry data $\left(l_{a}, h_{a}\right)$ of the cable in the unstressed configuration. Thus, we need another equation to serve as the additional condition for establishing the relationship between the reduced length $k l_{a}$, which equals $F\left(p, \phi_{0}\right)$ according to (9), and the geometry data $\left(l_{a}, h_{a}\right)$.

In derivation of the tip coordinates $\left(x_{a}, y_{a}\right)$ for the column in the deformed configuration, as shown in Fig. 2(a), the coordinate differentials $\left(d x_{a}, d y_{a}\right)$ can be related to the arc length differential $d s$ in terms of the column slope $\theta$ as follows

$$
\left\{\begin{array}{l}
d x_{a} \\
d y_{a}
\end{array}\right\}=\left\{\begin{array}{l}
\cos \theta \\
\sin \theta
\end{array}\right\} d s
$$

By transforming the column slope $\theta$ to the included angle $\theta+\alpha$, the relationship between the differential arc length $d s$ and coordinate differentials $\left(d x_{a}, d y_{a}\right)$ becomes

$$
\begin{aligned}
\left\{\begin{array}{c}
\cos (\theta+\alpha) \\
\sin (\theta+\alpha)
\end{array}\right\} d s & =\left[\begin{array}{l}
\cos \alpha \times(\cos \theta \times d s)-\sin \alpha \times(\sin \theta \times d s) \\
\sin \alpha \times(\cos \theta \times d s)+\cos \alpha \times(\sin \theta \times d s)
\end{array}\right] \\
& =\left[\begin{array}{cc}
\cos \alpha & -\sin \alpha \\
\sin \alpha & \cos \alpha
\end{array}\right]\left\{\begin{array}{l}
d x_{a} \\
d y_{a}
\end{array}\right\}
\end{aligned}
$$

By relating $d s$ to $d \theta$ using (4) and then to $d \phi$ using (8), the preceding equation can be manipulated to yield

$$
\begin{aligned}
\left\{\begin{array}{c}
\cos (\theta+\alpha) \\
\sin (\theta+\alpha)
\end{array}\right\} d s & =\left\{\begin{array}{c}
1-2 \sin ^{2}[(\theta+\alpha) / 2] \\
2 \sin [(\theta+\alpha) / 2] \times \cos [(\theta+\alpha) / 2]
\end{array}\right\} d s \\
& =\left\{\begin{array}{c}
-2\left(1-p^{2} \sin ^{2} \phi\right)-1 \\
2 p \sin \phi \times \sqrt{1-p^{2} \sin ^{2} \phi}
\end{array}\right\} d s \\
& =\left\{\begin{array}{c}
2 \sqrt{1-p^{2} \sin ^{2} \phi} d \phi / k-d s \\
-2 p \sin \phi d \phi / k
\end{array}\right\}
\end{aligned}
$$

Substituting (12) into (11) and integrating both sides of (11) with respect to the limits of the column, one can obtain the following for the tip coordinates $\left(x_{a}, y_{a}\right)$ of the column in the deformed configuration:

$$
\left[\begin{array}{cc}
\cos \alpha & -\sin \alpha \\
\sin \alpha & \cos \alpha
\end{array}\right]\left\{\begin{array}{l}
x_{a} \\
y_{a}
\end{array}\right\}=\left\{\begin{array}{c}
2 E\left(p, \phi_{0}\right) / k-l_{a} \\
2 p \cos \phi_{0} / k
\end{array}\right\}
$$

where

$$
\begin{aligned}
& E\left(p, \phi_{0}\right)=E_{e}(p, \pi / 2)-E_{e}\left(p, \phi_{0}\right) \\
& E_{e}(p, \pi / 2)=\int_{0}^{\pi / 2} \sqrt{1-p^{2} \sin \phi^{2}} d \phi \\
& E_{e}\left(p, \phi_{0}\right)=\int_{0}^{\phi_{0}} \sqrt{1-p^{2} \sin \phi^{2}} d \phi
\end{aligned}
$$

Here, $E_{e}(p, \pi / 2)$ is a complete elliptic integral of the second kind and $E_{e}\left(p, \phi_{0}\right)$ an incomplete elliptic integral of the second kind [17]. By the use of the relation $k l_{a}=F\left(p, \phi_{0}\right)$ in (9), one can solve (13) to obtain the tip coordinates $\left(x_{a}, y_{a}\right)$ of the column in the deformed configuration as follows:

$$
\left\{\begin{array}{l}
x_{a} \\
y_{a}
\end{array}\right\}=l_{a} \times\left[\begin{array}{cc}
\cos \alpha & \sin \alpha \\
-\sin \alpha & \cos \alpha
\end{array}\right]\left\{\begin{array}{c}
2 E\left(p, \phi_{0}\right) / F\left(p, \phi_{0}\right)-1 \\
2 p \cos \phi_{0} / F\left(p, \phi_{0}\right)
\end{array}\right\}
$$

On the other hand, the relationship between the coordinates $\left(x_{a}, y_{a}\right)$ and the inclination angle $\alpha$ can be obtained from the analytical geometry shown in Fig. 2(a) as

$$
\frac{h_{a}-y_{a}}{x_{a}}=\frac{\sin \alpha}{\cos \alpha}
$$

By substituting the expression of the tip coordinates $\left(x_{a}, y_{a}\right)$ in (15) into (16), the relation between the angles $\left(\theta_{0}, \alpha\right)$ [or $\left.\left(p, \phi_{0}\right)\right]$, the initial geometry data $\left(l_{a}, h_{a}\right)$ of the cable, and the reduced length $k l_{a}$, i.e., $F\left(p, \phi_{0}\right)$, can be expressed as follows:

$$
\frac{h_{a}}{l_{a}} \cos \alpha-\frac{2 p \times \cos \phi_{0}}{F\left(p, \phi_{0}\right)}=0
$$

Since the lengths $l_{a}$ and $h_{a}$ for describing the initial geometry of the inclined cable are known, for a given $p$, the inclination angle $\alpha$ can be solved from (17). As was stated, the reduced length $k l_{a}$ can be computed from (9), and the stretching force $T$ needed to keep the column in such an equilibrium state is simply $T=E I k^{2}$.

\section{RANGE OF PROBLEMS CONSIDERED}

For the case when the included angle $\left(\theta_{0}+\alpha\right)$ reaches $\pi$, as shown in Fig. 3, the values of the parameter pair $\left(p, \phi_{0}\right)$ are: 


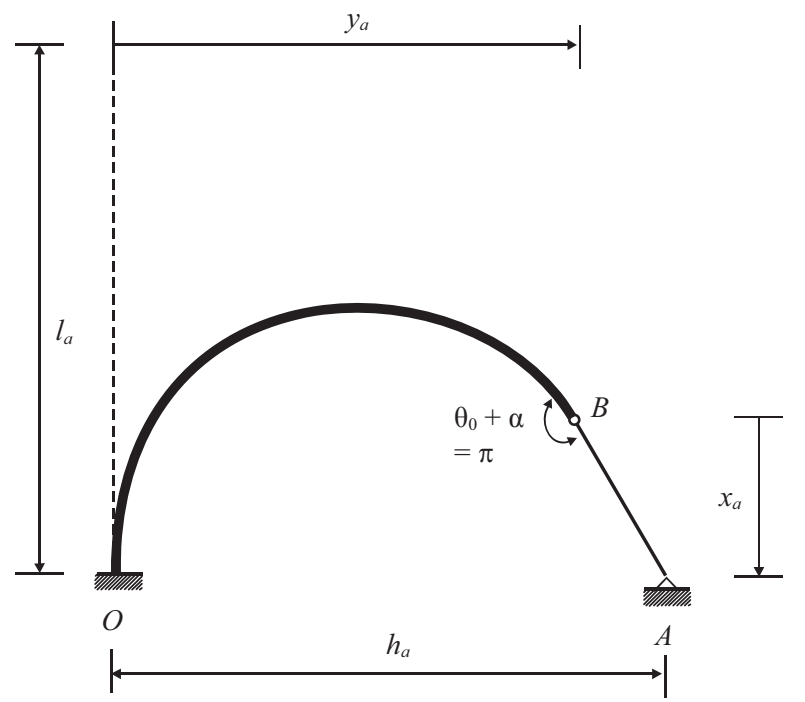

Fig. 3. Critical state of a guyed column pulled by an inclined cable: $\left(x_{a}>\right.$ $\left.0, h_{a}-y_{a}>0, \pi / 2>\alpha>0\right)$.

$p=1, \phi_{0}=\alpha / 2$ according to (6). Correspondingly, the elliptic integral $F\left(p, \phi_{0}\right)$ in (9) becomes

$$
F\left(1, \frac{\alpha}{2}\right)=\int_{\alpha / 2}^{\pi / 2} \frac{d \phi}{\sqrt{1-\sin \phi^{2}}}=\ln \left[\tan \left(\frac{\pi}{4}+\frac{\phi}{2}\right)\right]_{\alpha / 2}^{\pi / 2}
$$

which is infinitive, indicating that a limit point occurs when the condition $\theta_{0}+\alpha=\pi$ is reached. For a given $\theta_{0}$, the value of $\alpha$ that may result in such a limit point is just circumvented in this study.

During the stretching stage by the inclined cable as shown in Fig. 2, the tip slope $\theta_{0}$ is always greater than 0 . For the present case, only the case with $0<\theta_{0}<\pi$ is considered. For a given value of $\theta_{0}$, together with the $\alpha$ value solved from the nonlinear equations described above, the corresponding stretching cable force $T$ can be determined. It should be noted that the sign of $\alpha$ solved must be consistent with the physical position of the tip $B$ with coordinates $\left(x_{a}, y_{a}\right)$, that is,

(a) $0<\theta_{0} \leq \pi / 2$

(1) $x_{a}>0, h_{a}-y_{a}>0, \pi / 2>\alpha>0$, (see Fig. 3 );

(2) $x_{a}>0, h_{a}-y_{a}<0,-\pi / 2<\alpha<0$, (see Fig. 4);

(b) $\pi / 2<\theta_{0} \leq \pi$

(3) $x_{a}>0, h_{a}-y_{a}<0,-\pi / 2<\alpha<0$, (see Fig. 5);

(4) $x_{a}<0, h_{a}-y_{a}<0,-\pi<\alpha<-\pi / 2$, (see Fig. 6);

Figure 7 shows a tri-phase plot of the relations for the aspect ratio $h_{a} / l_{a}$, tip slope $\theta_{0} / \pi$, and reduced length ratio $k l_{a} / \pi$. There exists a curved ridge for which the condition $\theta_{0}+\alpha=\pi$ is satisfied. It can be observed that the larger the aspect ratio $h_{a} l_{a}$ is, the smaller the corresponding critical tip slope.

Next, let us consider a special case shown in Fig. 8, where

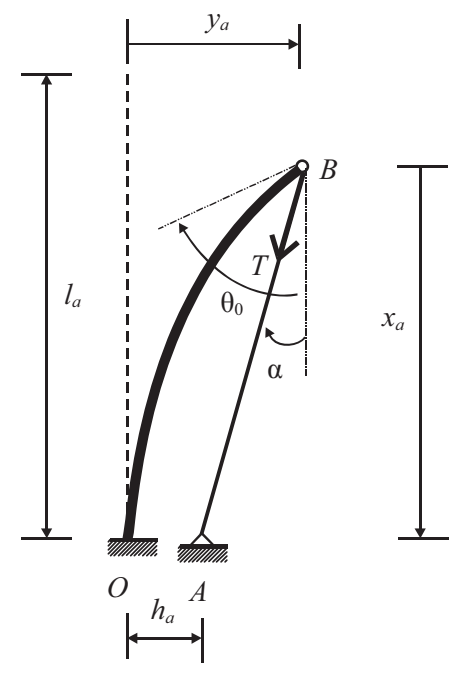

Fig. 4. Different deformed configurations of a guyed column: $x_{a}>0, h_{a}-$ $y_{a}<0,-\pi / 2<\alpha<0$.

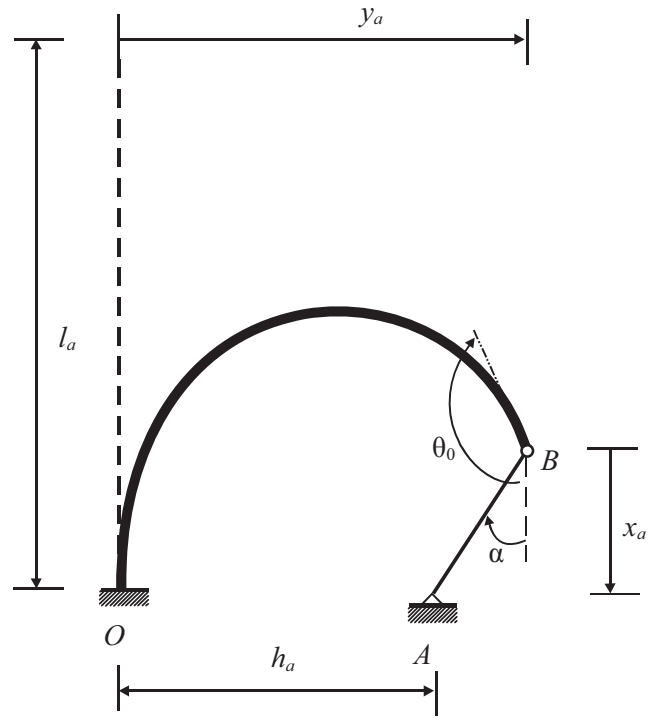

Fig. 5. Different deformed configurations of a guyed column: $x_{a}>0, h_{a}-$ $y_{a}<0,-\pi / 2<\alpha<0$.

the support end of the inclined cable just passes through the column base, that is $h_{a}=0$. According to (17), one can show that $\cos \phi_{0}=0$ or $\phi_{0}= \pm \pi / 2$. For the non-trivial case with $\phi_{0}=$ $-\pi / 2$ and for small deformation, the term $(p \sin \phi)^{2}$ may be neglected in comparison with unity in (9). It follows that the reduced length $k l_{a}$ becomes equal to $\pi$. From the definition of the buckling parameter of $k^{2}=T / E I$, it means that the critical pre-tensile force in the cable is: $T_{0}=E I k^{2}=E I\left(\pi / l_{a}\right)^{2}$. Such a result coincides with that derived by Timoshenko and Gere [24], which is the critical load of a compressed column with hinged ends [18]. The reason for such a phenomenon is concluded that as the stretched cable passes through both the tip and base of the cantilever column, the bending moment at the column base will vanish because the cable force applying to the bar is always at the same line of action [24]. 


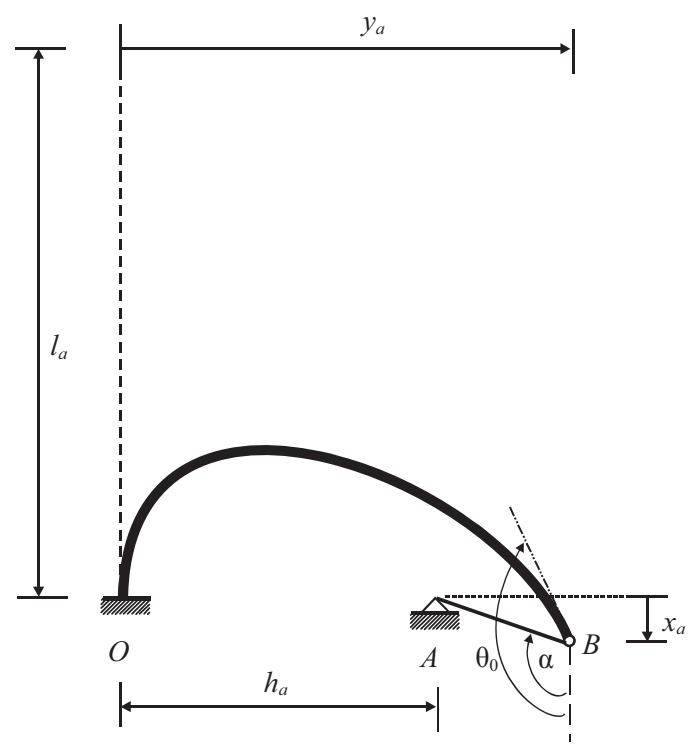

Fig. 6. Different deformed configurations of a guyed column: $\left(x_{a}<0\right.$, $h_{a}-y_{a}<0,-\pi<\alpha<-\pi / 2$.
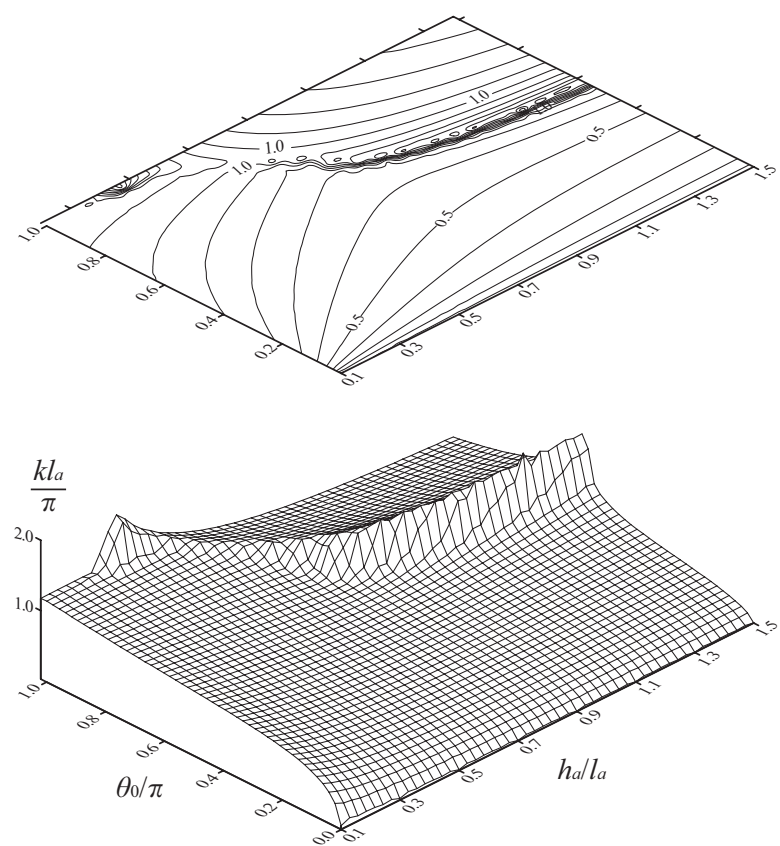

Fig. 7. Tri-phase plot of $k l_{a} / \pi-\theta_{0} / \pi-h_{a} / l_{a}$.

\section{CONCLUSION}

In the present study, the large deformation behaviors of a cantilever column guyed by one inclined cable are investigated. By modeling an inclination cable as an equivalent tensile bar, closed form solutions are derived for the guyed column with large deformation using an elliptic integral formulation. When a guyed column is subjected to the pull action of a cable with an inclination angle $\theta_{0}+\alpha$, the critical condition of the column occurs at $\theta_{0}+\alpha=\pi$. Based on an elliptic

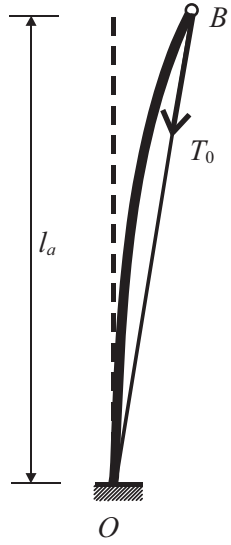

Fig. 8. Critical load of a pulled cable passing through the column base.

integral formulation proposed in references $[1,15]$, a closedform solution is derived for the large deflection of a guyed column pulled by a inclined pre-tensioned cable considering different cable supports. The present results can be used as a fundamental model to recognize the large deflection behaviors for cable supported structures subject to the sequentially applied cable forces with different stages. The analytical result indicates that the larger the aspect ratio $(h / l)$ of the cable anchor distance $(h)$ to the column height $(l)$ is, the smaller the corresponding critical tip slope will be.

\section{ACKNOWLEDGMENTS}

The author is grateful to anonymous referees for their valuable comments to this paper. Parts of the theory and illustrative examples presented in this study have been referred to as the extended abstracts entitled "Large Deflection Analysis of a Guyed Column Pulled by a Cable," presented at the Proceedings of IASS-APCS Symposium on New Perspectives for Shell \& Spatial Structures, National Taiwan University, Taipei, Taiwan, Oct. 22-25, 2003 [25].

\section{REFERENCES}

1. Atanackovic, T.-M., Stability Theory of Elastic Rods, World Scientific, Singapore (1997).

2. Chucheepsakul, S., Buncharoen, S., and Huang, T., "Elastica of a simple virable-arc-length beam subjected to an end moment," Journal of Engineering Mechanics, ASCE, Vol. 121, No. 7, pp. 767-772 (1995).

3. Chucheepsakul, S., Buncharoen, S., and Wang, C.-M., "Large deflection of beams under moment gradient," Journal of Engineering Mechanics, ASCE, Vol. 120, No. 9, pp. 1848-1860 (1994).

4. Chucheepsakul, S., Wang, C.-M., He, X.-Q., and Monprapussorn, T., "Double curvature bending of variable-arc-length elasticas," Journal of Applied Mechanics, ASME, Vol. 66, No. 1, pp. 87-94 (1999).

5. Conway, H.-D., "The large deflection of a simply supported beam," Philosophy Magazine: Series 7, Vol. 38, pp. 905-911 (1947).

6. Fertis, D. G., Nonlinear Mechanics, 2nd ed., CRC Press, Boca Raton (1999).

7. Gimsing, N.-J., Cable Supported Bridges: Concept and Design, 2nd ed., John Wiley, New York (1997).

8. Gospodnetic, D., "Deflection curve of a simply supported beam," Journal 
of Applied Mechanics, ASME, Vol. 26, No. 4, pp. 675-676 (1959).

9. Hartono, W., "On the post-buckling behavior of elastic fixed-end column with central brace," ZAMM-applied mathematics and mechanics, Vol. 81, No. 9, pp. 613-622 (2001).

10. Kalaga, S., and Adluri, S.-M.-R., "Beam-columns with finite deflections," Journal of Structural Engineering, ASCE, Vol. 126, No. 2, 266269 (2000).

11. Kuznetsov, V.-V. and Levyakov, S.-V., "Complete solution of the stability problem for elastica of Euler's column," International Journal of Non-Linear Mechanics, Vol. 37, pp. 1003-1009 (2002).

12. Lee, B.-K. and Oh, S.-J., "Elastica and buckling load of simple tapered columns with constant volume," International Journal of Solids and Structures, Vol. 37, pp. 2507-2518 (2000).

13. Nageswara, B.-R. and Venkateswara, G.-R., "On the large deflections of cantilever beams with end rotational load," ZAMM-applied mathematics and mechanics, Vol. 66, No. 10, pp. 507-509 (1986)

14. Ohtsuki, A. and Ellyin, F., "Large deformation analysis of a square frame with rigid joints," Thin-Walled Structures, Vol. 38, pp. 79-91 (2000).

15. Timoshenko, S.-P. and Gere, J.-M., Theory of Elastic Stability, 2nd ed. McGraw-Hill, New York (1961).

16. Timoshenko, S.-P. and Gere, J.-M., Mechanics of materials, New York, Van Nostrand Reinhold, 1972.

17. Tuma, J.-J., Handbook of Numerical Calculations in Engineering, McGraw-Hill, New York (1989).

18. Villaggio, P., Mathematical Models for Elastic Structures, 2nd ed., Cam- bridge University Press, Cambridge (1997).

19. Wang, C.-M. and Kitipornchai, S., "Shooting-optimization technique for large deflection analysis of structural members," Engineering Structures, Vol. 14, No. 4, pp. 231-240 (1992).

20. Wang, C.-M., Lam, K.-Y., He, X.-Q., and Chucheepsakul, S., "Large deflections of an end supported beam subjected to a point load," International Journal of Non-Linear Mechanics, Vol. 32, No. 1, pp. 63-72 (1997).

21. Williams, F.-W., "An approach to the non-linear behaviour of the members of a rigid jointed plane framework with finite deflections," Quarterly Journal of Mechanics and Applied Mathematics, XVII, Part 4, pp. 451469 (1964).

22. Yau, J.-D., "Stability of tapered I-beams under torsional moments," Finite Element in Analysis and Design, Vol. 42, No. 10, pp. 914-927 (2006).

23. Yau, J.-D., "Elastic stability of I-columns subjected to compressions and bi-moments," Journal of the Chinese Institute of Engineers, Vol. 30, pp. 569-578 (2007).

24. Yau, J.-D., "Lateral buckling analysis of angled frames with thin-walled I-beams," Journal of Marine Science and Technology, Vol. 17, No. 1, pp. 29-33 (2009)

25. Yau, J.-D. and Yang, Y.-B., "Large deflection analysis of a guyed column pulled by a cable," Extended abstracts of IASS-APCS Symposium on New Perspectives for Shell \& Spatial Structures, National Taiwan University, Taipei, Taiwan, Oct. 22-25 (2003). 